\title{
Characterization and in vitro Release Studies of Tetracycline and Rolitetracycline Imobilized on Anionic Collagen Membranes
}

\author{
Gilberto Goissis ${ }^{\mathrm{a} *}$, Maria Helena de Sousa ${ }^{\mathrm{b} *}$ \\ a Departamento de Produção, \\ Biotech Biomédica Produtos Médicos e Odontológicos Ltda. \\ Rua Santos Dumont, 800, Vila Celina, 13566-445 São Carlos - SP, Brazil \\ ${ }^{\mathrm{b}}$ Faculdade Farmácia, Campus de Jatai, \\ Universidade Federal de Goiás - UFG, Jatai - GO, Brazil
}

Received: June 20, 2008; Revised: January 6, 2009

\begin{abstract}
This work reports the covalent immobilization of tetracycline and rolitetracycline over anionic collagen membranes and the drug release studies as an effort to develop a two stage drug release based on diffusion (fast release) and on the rate of membrane biodegradation (slow release). Independent from casting conditions antibiotics incorporated by dispersion were released in the range from 80 to $100 \%$ within 7 hours in concentrations significantly higher than those described for the prevention of bacterial growth. Antibiotic release within this period was predominantly diffusion controlled. Covalent immobilization by a modified azide procedure occurred with preservation of collagen structure independently from $\mathrm{pH}$ of casting and reaction conditions. Its expected that anionic collagen membranes with dispersed and covalently bound rolitetracycline or tetracycline, in association with conventional therapy, may significantly reduce membrane induced infections observed post-implantation, one of the major problem associated with periodontal ligaments reconstruction by the Guided Tissue Regeneration procedure.
\end{abstract}

Keywords: antibiotic, immobilization, covalent, release, collagen, membranes

\section{Introduction}

Sustained drug release technology ${ }^{1}$ is being applied from protein hormones such as insulin for the treatment of diabetes ${ }^{2}$ to antibiotics for the prevention or minimization of bacterial infection ${ }^{3-5}$. Advantages of this technology are associated with reduction in side effects, decreased systemic toxicity and higher efficiency due to high drug concentrations at the site of damage ${ }^{6,7}$. Improvements on the field has also been based on the development new biocompatible synthetic ${ }^{8}$ and natural polymers ${ }^{9}$ and bioceramic $c^{4,10,11}$. Among the natural polymers, collagen has been investigated as natural candidate for drug delivery matrix due to its high biocompatibility, low antigenicity ${ }^{12,13}$, controlled biodegradability by cross-linking reagents ${ }^{13}$ and the easy that may form composites with ceramics or synthetic polymers ${ }^{4,15,16}$. Some examples include gentamicin supported in collagen sponges for the control of osteomyelitis, the prevention of wound infection in elective colorectal surgery and in ophthalmology, in the form therapeutic shields, containing cyclosporine and metilmicin for the promotion of corneal epithelial healing ${ }^{17}$. As with most sustained delivery systems involving molecules with low molecular masses, drugs release from collagen devices are predominantly diffusion controlled with high release coefficients, thus preventing long term maintenance of therapeutically levels ${ }^{18,19}$. One alternative way to modulate release over an extended period time would be through covalently binding of the drug so that sustained release may be maintained by the rate of biodegradation ${ }^{20}$. In association with diffusional mechanisms may provide highly efficient sustained drug delivery system for a variety of applications such as in the treatment of periodontal diseases ${ }^{21}$. For this purpose formulations include tetracycline fibber, doxycycline polymer, chlorhexidine chip, minocycline ointment and metronidazole $^{21}$. While this therapy produce favorable results for the control and elimination of the disease they are unsatisfactory for the treatment of the anatomical lesions produced by the disease. In this case the indicated treatment for periodontal tissue regeneration is the Guided Tissue Regeneration technique ${ }^{22}$. One significant advance in the field was the introduction of controlled biodegradable materials ${ }^{23,24}$ that in comparison to non-biodegradable polymers, do not require a second surgical intervention for membrane removal. One major problem with this technique is the membrane induced infections observed post implantation, a common event associated with the guided tissue regeneration procedure ${ }^{5,26}$.

This work reports the covalently immobilization of rolitetracycline and tetracycline over anionic collagen membranes (ACM) by a modified azide procedure or dispersion and the release studies, as an effort to develop a two stage release, based on diffusion (fast release) and on the rate of ACM biodegradation (slow release) ${ }^{14}$. ACM was the material of choice due to its biocompatibility, the ability of this membranes to reconstitute the periodontal ligaments ${ }^{23}$ and increased carboxyl groups content as a result of the selective hydrolysis of carboxyamides of asparagine and glutamine present in the collagen matrix ${ }^{15}$, thus allowing for a high level of antibiotic incorporation by esterification in comparison to native collagen biomaterials. Under these conditions the total $\mathrm{COOH} \mathrm{mEq} . \mathrm{g}^{-1}$ of collagen will be approximately 1.0 in comparison to 0.84 for native. 


\section{Material and Methods}

\subsection{Anionic collagen gels}

These were prepared after the treatment of bovine tendon with an alkaline solution, $6 \%$ in dimethylsulfoxide containing sulfate and chloride salts of sodium, potassium and calcium for a period of 24 hours (15). Excess salts were removed by extensive washes with $3 \%$ boric acid solution ( 3 times for 6 hours), 0.3\% EDTA pH 11.0 ( 3 times for 6 hours) deionized water ( 6 times for 2 hours) and after extraction with a $\mathrm{pH} 3.5$ acetic acid solution the concentration was adjusted to $1.0 \%\left(\mathrm{w} \cdot \mathrm{w}^{-1}\right)$. Part of the gel was dialyzed to equilibrium against a $\mathrm{pH} 7.4,0.13 \mathrm{M}$, phosphate buffer and after centrifugation at a $20{ }^{\circ} \mathrm{C}$ gel concentration was adjusted to $0.7 \%\left(\mathrm{w}^{-\mathrm{w}^{-1}}\right)$.

\subsection{Antibiotic immobilization}

\subsubsection{By dispersion on collagen gels}

The antibiotics under studies, of tetracycline (hydrochloride) and rolitetracycline (monohydrate $0.25 \mathrm{~mol}$ isopropanol) were dispersed in $0.7 \%\left(\mathrm{w}^{\mathrm{w}} \mathrm{w}^{-1}\right)$ collagen gels equilibrated at $\mathrm{pH} 3.5$. After homogenization, ACM were cast by the introduction of $7 \mathrm{~mL}$ of the dispersion in acrylic molds with $4.5 \mathrm{~cm}$ of diameter. The gels were dried under laminar flow at room temperature and protected from light. Antibiotics concentrations were respectively 0.87 and $0.92 \mathrm{mg}$ of tetracycline and rolitetracycline $/ \mathrm{cm}^{2}$ of collagen membrane. Similar procedure was used for membranes cast at $\mathrm{pH} 7.4$ except that dispersion of tetracycline was done on collagen gels previously equilibrated at pH 7.4 as described above.

\subsection{Covalent immobilization}

\subsubsection{Glutaraldehyde cross-linking}

Collagen membranes cast under the same conditions as described and after equilibration in PB buffer were immersed in a $0.05 \%$ glutaraldehyde solution in the same buffer for 15 minutes After this period the membranes were washed throughout with deionized water, dried under the same conditions as described above and submitted to the azide procedure as described in the literature ${ }^{27}$ except that the $0.2 \mathrm{M}$ hydrochloric solution in methanol was prepared by the reaction of thionyl chloride with methanol in order to assure complete anhydrous conditions in the esterification step.

\subsubsection{Esterification}

ACM were treated at $25{ }^{\circ} \mathrm{C}$ with $30 \mathrm{~mL} / \mathrm{membranes}$ with a methanol: $\mathrm{HCl}, 0.2 \mathrm{M}$ for a period of 4 and 7 days with continuous agitation. After this period, ACM was washed 6x with $20 \mathrm{~mL}$ of $1.0 \mathrm{M} \mathrm{NaCl}$ solution. The methanol: $\mathrm{HCl}$ solution was prepared by the addition of $1.8 \mathrm{~mL}$ of thionyl chloride over the alcohol $(200 \mathrm{~mL})$ followed by titration ${ }^{28}$.

\subsubsection{Hydrazinolysis}

ACM was treated at $25^{\circ} \mathrm{C}$ with a $100 \mathrm{~mL} / \mathrm{ACM}$ of a $1 \%$ hydrazine solution in $\mathrm{NaCl} 1.0 \mathrm{M}$ for a period of 24 hours. After this periods $\mathrm{ACM}$ was washed as described in the esterification procedure.

\subsubsection{Azide formation and antibiotic incorporation}

ACM were suspended in $30 \mathrm{~mL}$ of a $1.0 \mathrm{M} \mathrm{NaCl}$ solution made $0.5 \mathrm{M}$ in $\mathrm{NaNO}_{2} 0.3 \mathrm{M}$ cooled to $4{ }^{\circ} \mathrm{C}$ and the reaction allowed to proceed for 3 minutes. After this period ACM was washed $3 \mathrm{x}$ with PB $\left(4{ }^{\circ} \mathrm{C}\right)$ followed by the addition of $50 \mu \mathrm{moL}$ of antibiotic $(22 \mathrm{mg}$ of tetracycline; $28.3 \mathrm{mg}$ of rolitetracycline/ACM) dissolved in $30 \mathrm{~mL}$ of PB and the reaction allowed to proceed for a period of 20 days. Disappearance of antibiotic from solution was performed by UVspectroscopy at $269.0 \mathrm{~nm}\left(\lambda_{\max }\right.$ for tetracycline $)$ and $271.6 \mathrm{~nm}\left(\lambda_{\max }\right.$ for rolitetracycline).

\subsection{Material characterization}

\subsubsection{Infrared spectroscopy (IR)}

Infrared absorption spectra were obtained from $0.4 \mathrm{mg} \cdot \mathrm{cm}^{-2} \mathrm{mem}-$ branes prepared as described above except from $0.35 \%$ collagen gel at $\mathrm{pH}$ 3.5. Collagen IR absorption spectra were recorded from 400 to $4,000 \mathrm{~cm}^{-1}$ with a resolution of $4 \mathrm{~cm}^{-1}$, in a Bomen FTIR MB-120 spectrophotometer and the $1,235 / 1,450 \mathrm{~cm}^{-1}$ ratio compared with that of gelatin membranes for comparative IR for the measure of collagen triple helix integrity.

\subsubsection{Thermal stability}

Was determined as shrinkage temperature (Ts) with $2.0 \times 0.2 \mathrm{~cm}$ strips of collagen membranes in a melting point equipment adapted for Ts evaluations. Materials were immersed in the phosphate buffer (PB) with samples enclosed in a $20 \mathrm{~mm}$ graduated Pyrex tubing, immersed in a silicone oil bath. Heating rate was fixed at $2.0^{\circ} \mathrm{C} / \mathrm{min}$, from room temperature up to $120^{\circ} \mathrm{C}$. Ts values correspond to the average of 3 independent determinations.

\subsection{Release studies}

Membranes with antibiotic incorporated by dispersion (tetracycline and rolitetracycline) or by the azide procedure (tetracycline) were fixed in a chamber containing $150 \mathrm{~mL}$ of saline phosphate buffer (PBS) $\mathrm{pH} 7.4$ with the temperature kept at $37 \pm 0.1{ }^{\circ} \mathrm{C}$ and continuous stirring. Release studies were performed by UV absorption readings at 271.6 and $269.0 \mathrm{~nm}$ for rolitetracycline and tetracycline in an UV-visible spectrophotometer HITACHI ${ }^{\circledR}$ Mod. U-1100 in samples removed for a period of 7.5 hours. The volumes of removed samples were immediately replaced with the same volume of PBS.

\section{Results and Discussion}

The ratio for the infrared absorbances of bands $1,235 / 1,450 \mathrm{~cm}^{-1}$ determined for anionic collagen membranes cast from bovine tendon at $\mathrm{pH} 3.5$ and 7.4, which is a measure of integrity of the triple helix structure ${ }^{29}$ were 1.0 e 1.1 respectively, suggesting that collagen triple helix secondary structure was preserved. Typical values for collagen membranes cast under some conditions are close to 1.0 while those for denatured collagen and gelatin membranes are significantly lower and in the range of $0.60^{29}$. The infrared spectrum of membranes with antibiotics did not show any bands due to incorporated antibiotics, probably due to their low concentration.

The maintenance of collagen triple helix secondary structure was also confirmed by thermal stability determined as Ts since independently the antibiotic immobilization procedure (dispersion or azide) all ACM were characterized by thermal transitions, which is absent in denatured collagen materials (Table 1) in the temperature range studied. For ACM cast at $\mathrm{pH} 3.5$ and 7.4 and in the absence of antibiotics Ts values were respectively $49.1 \pm 0,7$ and $58.0 \pm 0.6{ }^{\circ} \mathrm{C}$. The higher thermal stability found for ACM equilibrated at $\mathrm{pH} 7.4$ is in agreement with the disruption of collagen macromolecular fibrillar assembly that is known to occur with collagen matrices submitted solution with $\mathrm{pH}$ lower than $4.25^{30}$. After glutaraldehyde crosslinking these values increased $77.9 \pm 0.2$ and $77.3 \pm 0.4{ }^{\circ} \mathrm{C}$ (Table 1) as described for similar ACM with controlled biodegradability and 
used in the treatment of periodontal diseases by the guided tissue regeneration technique ${ }^{14,23}$.

No significant changes were detected in Ts for ACMs equilibrated at $\mathrm{pH} 3.5$ or 7.4 with rolitetracycline and tetracycline incorporated by dispersion (Table 1) suggesting the absence of any interaction between ACM and the antibiotics.

Release studies of rolitetracycline and tetracycline incorporated by dispersion on ACM cast at $\mathrm{pH} 3.5$ (Figure 1a, curves a and b) showed that after 4 hours these antibiotic were almost completely released from RCM and at levels of respectively $86.6 \pm 1.5$ and $97.2 \pm 2.1 \%$. After 7.5 hours the amount released were respectively $92.2 \% \pm 0.6$ and $98.5 \pm 0.7$. For tetracycline dispersed on RCM cast from gels previously equilibrated at $\mathrm{pH} 7.4$, the amount of antibiotic release after 3 hours was $84.5 \pm 1.2 \%$ remainning constant after this period (Figure 1a, curve c), and may be attributed to electrostatic binding of the antibiotic (a cation at this $\mathrm{pH}$ ) to the polyanionic $\mathrm{RCM}^{14}$.

Under these conditions the average rolitetracycline concentration that may be immediately released within the periodontal pocket post surgically in the first 4 hours period will be $489.78 \mu \mathrm{g} \cdot \mathrm{mL}^{-1} / \mathrm{h}$, which is significantly higher than MIC values for this antibiotic and of $8 \mu \mathrm{g} . \mathrm{mL}^{31}$ and compatible with the necessary concentration of $150 \mu \mathrm{L} / \mathrm{h}$ established as ideal in the gingival flow ${ }^{32}$. After this time (Figure 1a, curve b), during the remaining 3.5 hours post operation, the average rolitetracycline release would be $69.1 \mu \mathrm{g} . \mathrm{mL} / \mathrm{h}$ which is still significantly higher than MIC for this antibiotic. With tetracycline effective concentration was observed only within the first 4 hours with an average release of $422.8 \mu \mathrm{g} \cdot \mathrm{mL}^{-1} / \mathrm{h}$. The calculations above were based on the amount of antibiotic present in $2 \mathrm{~cm}^{2}$ of ACM, the average of membrane size normally used in the treatment of furcation II lesion ${ }^{23}$. Under these conditions the total disposable tetracycline and rolitetracycline concentration will be 1.7 and $1.8 \mu \mathrm{g}$.

Antibiotics release from ACM for releases from 60 to $70 \%$ were analyzed by means of the Higuchi equation $\mathrm{M}_{\mathrm{t}}=\mathrm{Kt}^{\mathrm{n} 33}$ and independent from the antibiotic or membrane casting conditions showed values of $\mathrm{n}$ close to 0.50 (Figure $1 \mathrm{~b}$, Table 2). These results suggest that most of the antibiotics are released from ACM predominantly by diffusion with high release coefficient. The calculated Higuchi constants for tetracycline and rolitetracycline in ACM cast from gels equilibrated at pH 3.5 were respectively $0.80 \pm 0.02$ and $0.75 \pm 0.02 \mathrm{~g} . \mathrm{h}^{1 / 2}$ (Table 2). For tetracycline dispersed in membranes cast at $\mathrm{pH} 7.4$ in ACM cast the Higuchi constant was $0.88 \pm 0.02$. Correlation coefficient in all cases were close to 0.99 (Table 2). These results are consistent with those described for sustained delivery systems involving collagen matrices and drugs with small molecular masses ${ }^{19-21}$.

Glutaraldehyde cross-linking was performed under the same conditions as described for ACM used in the biocompatibility and

Table 1. Shrinkage temperature $\left(\mathrm{Ts},{ }^{\circ} \mathrm{C}\right)$ of reconstituted collagen membranes without and with antibiotics incorporated by dispersion or by covalent immobilization by azide procedure.

\begin{tabular}{|c|c|c|c|c|c|}
\hline \multirow{3}{*}{ Antibiotic } & \multicolumn{5}{|c|}{ Incorporation procedure } \\
\hline & \multicolumn{2}{|c|}{ Dispersion } & \multicolumn{3}{|c|}{ Azide } \\
\hline & $\mathrm{pH} 3.5$ & pH 7.4 & $\mathrm{GA}^{\mathrm{b}}$ & 4 days $^{c}$ & 7 days $^{\mathrm{c}}$ \\
\hline $\mathrm{RCM}$ & $49.1 \pm 0.7$ & $58.0 \pm 0.6$ & $79,0 \pm 0,5$ & $77.9 \pm 0.2$ & $77.3 \pm 0.4$ \\
\hline RCM+Rolitetracycline & $49.8 \pm 0.3$ & $57.8 \pm 0.7$ & - & $78.7 \pm 0.4$ & $78.2 \pm 0.7$ \\
\hline RCM+Tetracycline & $48.6 \pm 0.5$ & $59.5 \pm 0.5$ & - & - & $77.7 \pm 0.8$ \\
\hline
\end{tabular}

${ }^{\mathrm{a}}$ Average of 3 independent determinations; ${ }^{\mathrm{b}} \mathrm{Membranes}$ equilibrated at $\mathrm{pH} 3.5$; and ${ }^{\mathrm{c}}$ Time period for the esterification procedure of membranes equilibrated at $\mathrm{pH} 3.5$.

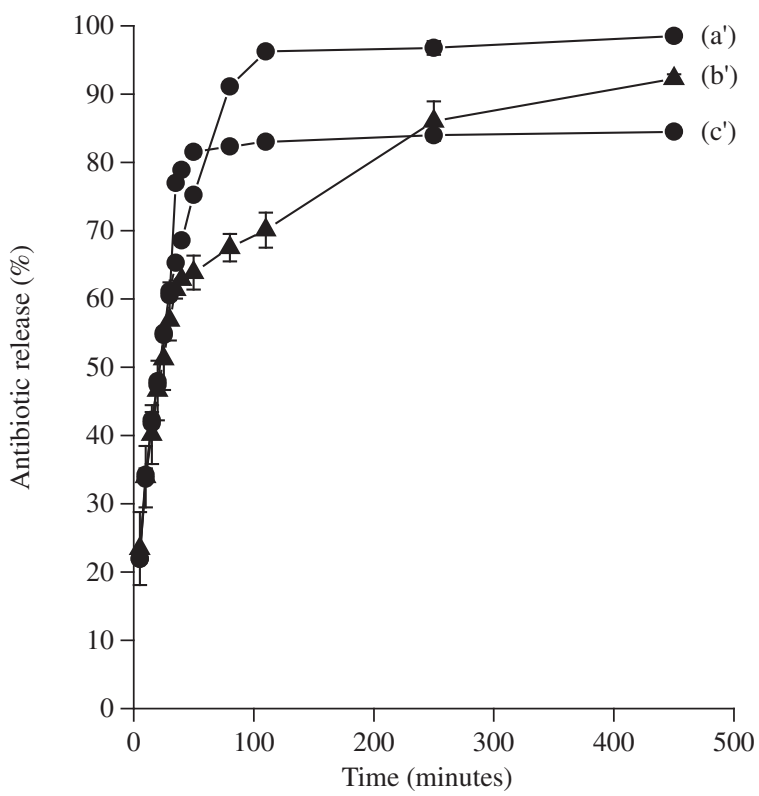

(a)

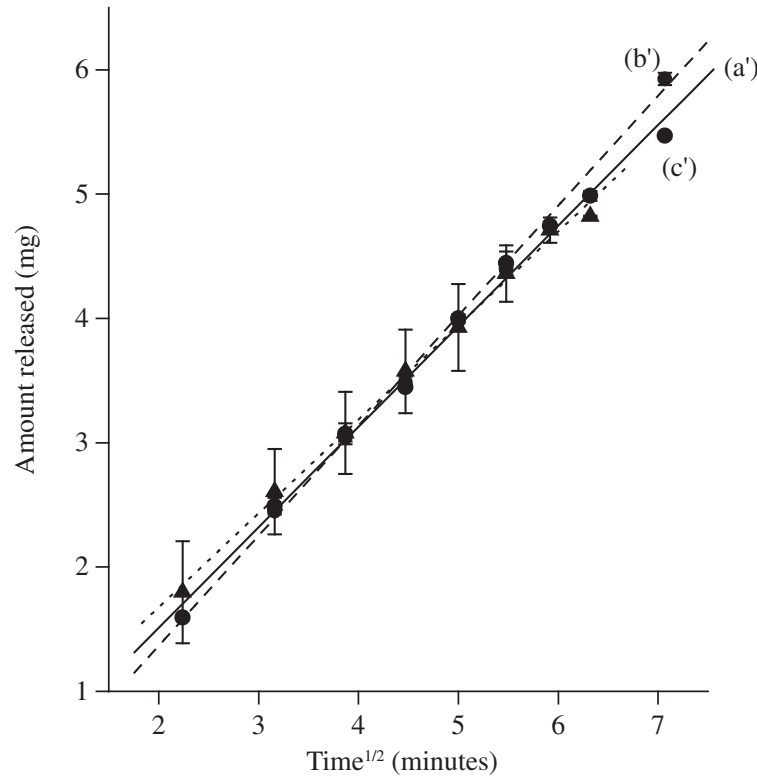

(b)

Figure 1. a) Antibiotic release and the b) Higuchi plot determined in anionic collagen membranes: for tetracycline (a') and rolitetracycline (b') from membranes cast at $\mathrm{pH} 3.5$ and for tetracycline from membranes cast at $\mathrm{pH} 7.4$ (c'). 
periodontal ligament repair studies ${ }^{14,23}$, a conditions where glutaraldehyde concentration is sufficient to promote complete reaction with free $\varepsilon$-amino groups of lysine residues (Schiff base formation). This was also necessary to avoid the formation of amide bond type of crosslinking that could be formed by reaction of the azide function with $\varepsilon$-amino groups of lysine and thus competing with antibiotic ester bond formation to the collagen matrix (Figure 2). This was indicated by maintenance of Ts values determined after the azide procedure for the introduction of the antibiotic by esterification and, described below.

Independently from $\mathrm{pH}$ casting conditions or the esterification period, Ts values in all case were similar to that found for ACM after glutaraldehyde cross linking and of $79.0 \pm 0.5^{\circ} \mathrm{C}$ (Table 1). For membranes cast at $\mathrm{pH} 3.5$ Ts values after 4 and 7 days esterification were respectively $77.9 \pm 0.2$ and $77.3 \pm 0.4^{\circ} \mathrm{C}$ (Table 1 ). After rolitetracycline immobilization by azide Ts values were $78.7 \pm 0.4$ and $78.2 \pm 0.7^{\circ} \mathrm{C}$. Under similar conditions and 7 days esterification introduction of tetracycline produced a $\mathrm{RCM}$ with a Ts values of $77.7 \pm 0.8^{\circ} \mathrm{C}$

Tabela 2. Kinetics parameters ${ }^{\mathrm{a}}$ the release of tetacycline and rolitetracycline dispersed in anionic collagen membranes at $37^{\circ} \mathrm{C}$

\begin{tabular}{lccc}
\hline \multicolumn{1}{c}{ Antibiotic } & \multicolumn{3}{c}{ Parameters } \\
\cline { 2 - 4 } & $\mathrm{K}_{\mathrm{Hig}}{ }^{\mathrm{a}}$ & $\mathrm{n}^{\mathrm{b}}$ & $\mathrm{r}^{\mathrm{c}}$ \\
\hline Rolitetracycline (pH 3.5) & $0.75 \pm 0.02$ & $0.46 \pm 0.02$ & 0.998 \\
Tetracycline (pH 3.5) & $0.80 \pm 0.02$ & $0.51 \pm 0.01$ & 0.997 \\
Tetracycline (pH 7.4) & $0.88 \pm 0.02$ & $0.56 \pm 0.01$ & 0.999
\end{tabular}

${ }^{a}$ Average of 3 independent determinations and determined for antibiotic release from 60 to $70 \%$ interval; ${ }^{b} \mathrm{n}$, indicative of the liberation mechanism; $\mathrm{n}=0.5$, Fickian diffusion and ${ }^{\mathrm{c}}$ correlation coefficient.
Other minor change, but significant change in routine was the preparation of methanol: $\mathrm{HCl}$ esterifying reagent by the addition of thionyl chloride to methanol in order guarantee complete anhydrous conditions, since esterification is probably the most sensitive step affecting process repeatability, in comparison to hydrazinolysis, azide formation and antibiotic incorporation. Under this conditions, the required amount of $\mathrm{HCl}$ for the acid catalyzed esterification of collagen is provided by the reaction of thionyl chloride with residual water present in the system. Besides, the reaction of methanol with thionyl chloride also generates the esterifying reagent dimethylsulphite ${ }^{28}$. Although the 7 day esterification procedure was established in advance based on the esterification data described for bovine pericardium intended for the manufacture of valvular bioprostheses ${ }^{27}$ a 4 day esterification procedure was also studied.

Results in Figure 3a (curves a and b) correspond to the disappearance of rolitetracycline in contact with azide ACM (membranes cast at $\mathrm{pH}$ 7.4) from solution showing that under the conditions used no significant difference in antibiotic incorporation was detected between membranes esterifyed for 4 days (Figure 3a) and 7 days (Figure 3b), suggesting esterification is over a 4 day period. After 21 days of reaction total antibiotic incorporation amounted to $9.3 \pm 1.6$ and $9.0 \pm 1.3 \mathrm{mg}$ for 4 and 7 days esterification respectively.

Nevertheless, extraction of ACM with PB showed that not all of the incorporated antibiotic by the membrane was covalently bound since $2.7 \pm 1.1$ and $2.5 \pm 0.9 \mathrm{mg}$ were removed from the 4 and 7 days esterifyed ACM respectively. Extractions were performed until no traces of antibiotic could be detected in solution by UV spectroscopy. As a result the total amount of rolitetracycline covalently bound to ACM after 4 and 7 days esterification were respectively $6.6(12.3 \mu \mathrm{Eq})$ and $6.5(12.5 \mu \mathrm{Eq}) \mathrm{mg} / \mathrm{RCM}$. Based on the average weight of ACM of $49.57 \pm 1.53 \mathrm{mg}$ and the number of $\mathrm{COOH}$ groups available for esterifi-
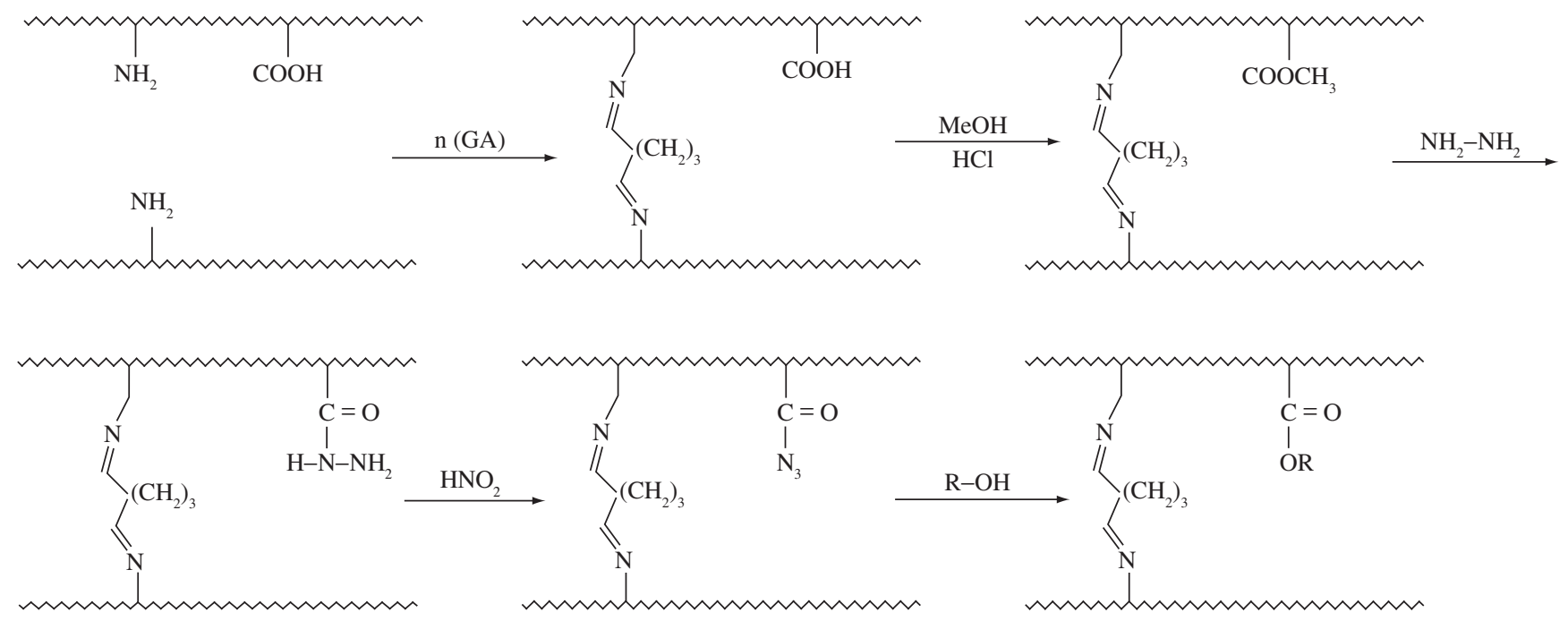

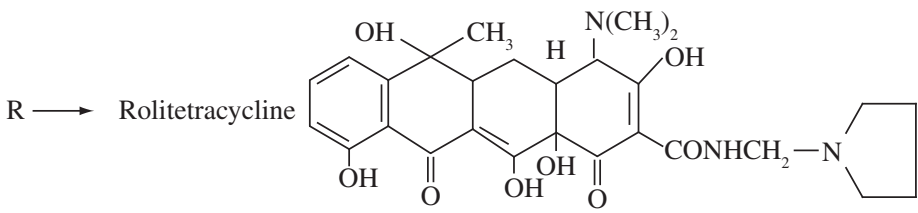

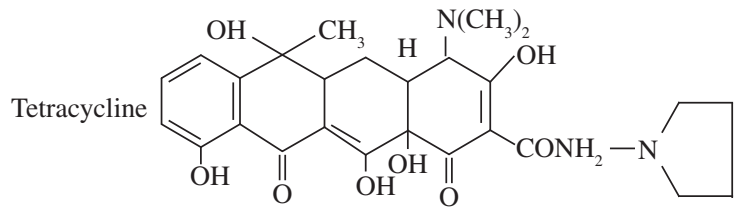

$\mathrm{GA}=$ Glutaraldehyde

Figure 2. Schematic representation the reaction steps involved in the incorporation of tetracycline and rolitetracycline aver anionic collagen membranes by the azide procedure 
cation of $1.07 \mu \mathrm{Eq} \cdot \mathrm{mg}^{-1}$, the yields for rolitetracycline incorporation for 4 and 7 days esterification were respectively 23.2 and $23.6 \%$, confirming the end of ACM esterification after 4 days of reaction.

Although the total incorporation of $14.1 \pm 0.19 \mathrm{mg}$ observed for tetracycline (Figure 3c) would suggest a more efficient covalent immobilization (Figure 3), $7.1 \pm 1.3 \mathrm{mg}$ of the antibiotic was extracted with PB. As a result, the total amount of antibiotic covalently bound to ACM was only around $7.0 \mathrm{mg}$, that based on the total amount of carboxyl groups available in ACM, corresponds to an yield of reaction $29.6 \%$.

Assuming for the ACM used in this work a biodegradation period of 40 days and that in the treatment of periodontal diseases approximately $2 \mathrm{~cm}^{2}$ of membrane is normally used ${ }^{23}$ the calculated amount of free antibiotic in the periodontal pocket for rolitetracycline and tetracycline will be respectively 0.85 and $0.91 \mu \mathrm{g} / \mathrm{h}$. Although slow release biodegradable devices intended for the control of periodon-

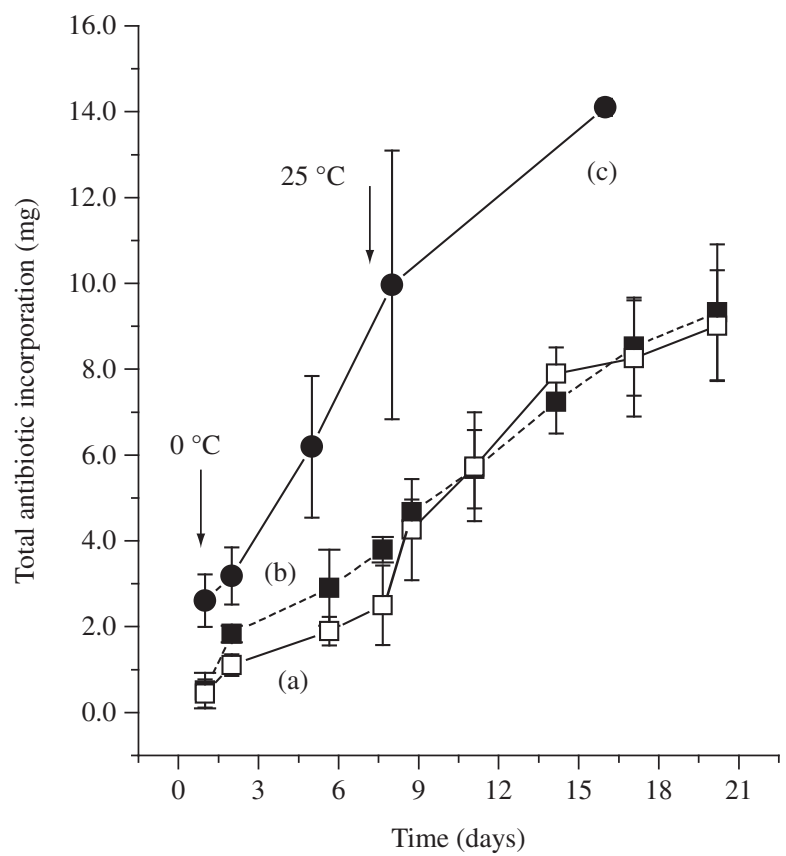

Figure 3. Incorporation profile determined by UV-visible spectroscopy of antibiotics for azide anionic collagen membrane cast from gels equilibrated at $\mathrm{pH}$ 7.4. a) rolitetracycline, 4 days esterification, b) rolitetracycline, 7 days esterification; c) tetracycline, 7 days esterification.

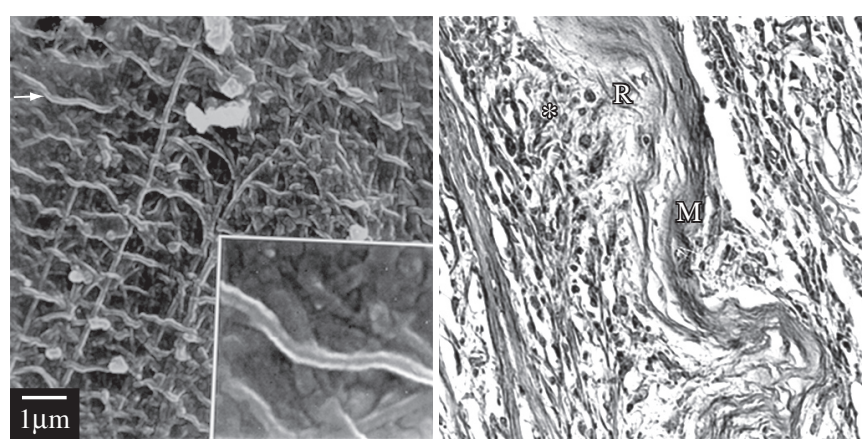

Figure 4. Reconstituted collagen membrane cast from tendon gel at $\mathrm{pH}$ 7.4: a) Scanning electron microscopy; and b) Optical microscopy after 20 days from implantation in the dog periodont (Hematoxilin and Eosine staining, 40x). tal diseases are characterized by higher rates of antibiotic releases within the periodontal pocket $\mathrm{t}^{21,33,34}$ the numbers for tetracycline and rolitetracycline described above are close to the serum concentrations observed for doxycycline in oral administration and in the range from 0.91 to $2.26 \mu \mathrm{g} . \mathrm{mL}^{-1}$ over the first 8 days $^{33}$.

As shown in Figure 4a ACM membranes cast at $\mathrm{pH}$ at $\mathrm{pH} 7.4$ is still characterized by the presence of the collagen microfibril structure in spite of the increase in negative charge content at physiological $\mathrm{pH}$ and preliminary result in the dog periodontium after 20 days from implantation was characterized by a high degree of biocompatibility (Figure 4b).

\section{Conclusions}

The results above showed that rolitetracycline or tetracycline incorporated by dispersion over ACM may be immediately released within the periodontal pocket post surgically with concentrations which are significantly higher than MIC values for this antibiotic and compatible with the necessary ideal concentration in the gingival flow. Independent from the antibiotic or membrane casting conditions, up to 60 to $70 \%$ release, the Higuchi equation suggest that most of the antibiotics are released from ACM predominantly by diffusion in association with high release coefficient, in agreement with sustained delivery systems involving collagen matrices and drugs with small molecular masses. The azide procedure showed that under the conditions used covalent immobilization was achieved at levels in the range from 23 to $29 \%$ (calculated on the basis of the total $\mathrm{COOH}$ groups available for esterification) and independently from $\mathrm{pH}$ casting and esterification conditions or reaction time (methyl ester formation or antibiotic incorporation) collagen structure was preserved in all cases. Although esterification yields may be considered low, it is expected that ACM with dispersed and covalently bound rolitetracycline or tetracycline and in association with conventional therapy will reduce membrane induced infections observed post implantation, a major problem associated with ligaments reconstruction by the Guided Tissue Regeneration procedure applied treatment of periodontal diseases $^{25,26}$.

\section{Acknowledgements}

Thanks to Ezer Biazin and Glauco D. Broch for technical assistance. This work was supported by PADCT, $\mathrm{n}^{\circ} 62.0001$ and RHAE/ CNPq $n^{\circ}$ 610.490. M.H. Sousa was a fellowship from CNPq at the Master Post-graduation in Physicochemistry at the Inst. of Chem. São Carlos - Universidade de São Paulo

\section{References}

1. Greenstein G. Local drug delivery in the treatment of periodontal diseases: assessing the clinical significance of the results. Journal of Periodontology. 2006; 77(4):565-578.

2. Obaidat AA, Park K. Characterization of protein release through glucosesensitive hydrogel membranes. Biomaterials. 1997; 18(11):801-806.

3. Meyer JD, Falk RF, Kelly RM, Shively JE, Withrow SJ, Dernell WS, Kroll DJ, Randolph TW, Manning MC. Preparation and in vitro characterization of gentamicin-impregnated biodegradable beads suitable for treatment of osteomyelitis. Journal of Pharmaceutical Sciences. 1998; 87 (9):1149-1154.

4. Martins VC, Goissis G, Ribeiro AC, Marcantonio Jr. E, Bet MR. The controlled release of antibiotic by hydroxyapatite: anionic collagen composites. Artificial Organs. 1998; 22(3):215-221.

5. Kwok CS, Horbett TA, Ratner BD. Design of infection-resistant antibioticreleasing polymers. II. Controlled release of antibiotics through a plasma-deposited thin film barrier. Journal of Controlled Release. 1999 62(3):301-311. 
6. Florence AT, Jani PU. Novel oral drug formulations their potential in modulating adverse effects. Drugs. 1996; 10(3):233-266.

7. Dash AK, Cudworth GC. Therapeutic applications of implantable drug delivery systems. Journal of Pharmacological and Toxicological Methods. 1998; 40(1):1-12.

8. Schierholz JM, Steinhauser H, Rump AF, Berkels R, Pulverer G. Controlled release of antibiotics from biomedical polyurethane: morphological and structural features. Biomaterials. 1997; 18(12):839-844.

9. Hari PR, Chandy T, Sharma CP. Chitosan/calcium alginate microcapsules for intestinal delivery of nitrofurantoin. Journal Microencapsulation. 1996; 13(3):319-329.

10. Itokazu M, Matsunaga T, Kumazawa S, Yang W. A novel drug delivery system for osteomyelitis using porous hydroxyapatite blocks loaded by centrifugation. Journal of Applied Biomaterials. 1995; 6(3):167-169.

11. Itokazu M, Ohno T, Tanemori T, Wada E, Kato N, Watanabe K. Antibiotic-loaded hydroxyapatite blocks in the treatment of experimental osteomyelitis in rats. Journal of Medical Microbiology. 1997; 46(9):779-783.

12. Chvapil M. Reconstituted collagen. In Biology of collagen. Viidik A, Vuust J. (Ed.). London: Academic Press; 1980.

13. Rao KP, Joseph T. Collagen graft copolymers and their biomedical applications. In Collagen Biotechnology. Nimni ME. (Ed). Boca Raton: CRC Press Inc.; 1988.

14. Goissis G, Marcantônio Jr. E, Marcantônio RAC, Lia RCC, Cancian DCJ, Carvalho WM. Biocompatibility studies of anionic collagen membranes with different degree of glutaraldehyde cross-linking. Biomaterials. 1999; 20(1):27-34.

15. Goissis G, Piccirili L, Goes JC, De Guzzi Plepis AM, Das-Gupta DK. Anionic collagen: polymer composites with improved dielectric and rheological properties. Artificial Organs. 1998; 22(3):203-209.

16. Omura S, Mizuki N, Horimoto S, Kawabe R, Fujita K. A newly developed collagen/silicone bilayer membrane as a mucosal substitute: a preliminary report. British Journal of Oral and Maxillofacial Surgery. 1997; 35(2):85-91.

17. Rao KP. Recent developments of collagen-based materials for medical applications and drug delivery systems. Journal of Biomaterials Science Polymer. 1995; 7(7):623-645.

18. Wachol-Drewek Z, Pfeiffer M. Comparative investigation of drug delivery of collagen implants saturated in antibiotic solutions and sponge containing gentamicin. Biomateriais. 1996; 17(17):1733-1738.

19. Singh MP, Stefko J, Lumpkin JA, Rosenblatt J. The effect of electrostatic charge interactions on release rates of gentamicin from collagen matrices. Pharmaceutical Research. 1995; 12(18):1205-1210.

20. Lin SS, Ueng SW, Liu SJ, Chan EC, Chao EK, Tsai CH, Chen KT, Wei FC, Shih CH. Development of a biodegradable antibiotic delivery system. Clinical Orthopaedics. 1999; 362:240-250.
21. Killoy WJ. Chemical treatment of periodontitis: local delivery of antimicrobials. International of Dental Journal. 1998; 48(3):305-315.

22. Nyman S, Gottlow J, Karring T, Lindhe J. The regenerative potential of the periodontal ligament: an experimental study in the monkey. Journal of Clinical Periodontology. 1982; 9(3):257-265.

23. Cirelli JA, Marcantônio Jr. E, Marcantônio RAC, Lia RCC, Rossa Jr. C, Goissis G. Evaluation of anionic collagen membranes in the treatment of class II furcation lesions: an histometric analysis in dogs. Biomaterial. 1997; 18(18):1227-1234.

24. Vernino AR, Ringeisen TA, Wang HL, Derhalli M, Rapley J, Nechamkin SJ, Brekke J. Use of biodegradable polylactic acid barrier materials in the treatment of grade II periodontal furcation defects in humans-Part I: a multicenter investigative clinical study. Internationl Journal of Periodontics Restourative Dentistry. 1998; 18(6):572-585.

25. Zucchelli G, Cesari C, Clauser C, De Sanctis M. Early bacterial accumulation on guided tissue regeneration membrane materials: an in vivo study. Journal Periodontology. 1998; 69(11):1193-1202.

26. Murphy KG. Postoperative healing complications associated with Gore-Tex Periodontal Material. Part I. Incidence and characterization. International Journal of Periodontics Restourative Dentistry. 1995; 15(4):363-375.

27. Petit H, Rault I, Huc A, Menasche P, Herbage D. Use of the acyl azide method for crosslinking collagen rich tissues such as pericardium. Journal of Biomedical Material Research. 1990; 24(2):93-107.

28. Campana SP, Goissis G. Kinetic and yield of the esterification of aminoacids with thionyl chloride: n-propanol. Journal of Chromatography. 1982; 236:179-187.

29. Huc A. Collagen biomaterials characteristics and applications. Journal of American Leather Chemical Association. 1985; 80:195-203.

30. Silvester MF, Yannas IV, Forbes MJ. Collagen banded fibril structure and the collagen platelet reaction. Trombosis Research. 1989; 55(1):135-148.

31. Minabe M, Uematsu A, Nishima K, Tomomatsu E, Tamura T, Hori T, Uemoto T, Hino T. Application of a local drug delivery system to periodontal therapy. Journal. Periodontology. 1989; 60(2):113-120.

32. Goodson JM. Dental applications. In Medical applications of controlled release. Langer SR, Wise LD. (Ed.). Boca Raton: CRC Press Inc.; 1984.

33. Stoller NH, Johnson LR, Trapnell S, Harrold CQ, Garrett S. The pharmacokinetic profile of a biodegradable controlled-release delivery system containing doxycycline compared to systemically delivered doxycycline in gingival crevicular fluid, saliva, and serum. Journal Periodontology. 1998; 69(10):1085-1091.

34. Jones DS, Woolfson AD, Djokic J, Coulter WA. Development and mechanical characterization of bioadhesive semi-solid, polymeric systems containing tetracycline for the treatment of periodontal diseases. Pharmaceutical Research. 1996; 13(11):1734-1738. 